OPEN ACCESS

Edited by:

Jianguo Liu,

Hefei Institutes of Physical Science

(CAS), China

Reviewed by:

Zhenguo Wang,

National University of Defense

Technology, China

Venugopal Rao Soma,

University of Hyderabad, India

*Correspondence:

Xin Yu

yuxin0306@hit.edu.cn

Specialty section:

This article was submitted to

Optics and Photonics,

a section of the journal

Frontiers in Physics

Received: 12 November 2019

Accepted: 18 March 2020

Published: 28 April 2020

Citation:

Peng J, Cao Z, Yu X, Yang S, Yu Y, Ren H, Zhang S, Chang G, Chen S,

Zhao Y, Yan B and Luo Y (2020)

Continuous 500- $\mathrm{Hz} \mathrm{OH}-\mathrm{PLIF}$

Measurements in a Hydrogen-Fueled

Scramjet Combustor.

Front. Phys. 8:101

doi: 10.3389/fphy.2020.00101

\section{Continuous 500-Hz OH-PLIF Measurements in a Hydrogen-Fueled Scramjet Combustor}

\author{
Jiangbo Peng ${ }^{1,2}$, Zhen Cao ${ }^{1,2}$, Xin Yu ${ }^{1,2 *}$, Shunhua Yang ${ }^{3}$, Yang Yu ${ }^{1,2}$, Hongyu Ren ${ }^{3}$, \\ Shunping Zhang ${ }^{3}$, Guang Chang ${ }^{1,2}$, Shuang Chen ${ }^{3}$, Yanhui Zhao ${ }^{3}$, Biao Yan ${ }^{1,2}$ and \\ Ye Luo ${ }^{1,2}$ \\ ${ }^{1}$ National Key Laboratory of Science and Technology on Tunable Laser, Harbin Institute of Technology, Harbin, China, \\ ${ }^{2}$ School of Astronautics, Harbin Institute of Technology, Harbin, China, ${ }^{3}$ China Aerodynamics Research and Development \\ Center, Mianyang, China
}

In recent years, significant research attention has focused on scramjet bench-testing using optical measurement techniques to obtain significant experimental data. The work aims to verify the environmental reliability of high-speed planar laser-induced fluorescence (PLIF) technique and satisfy bench-test requirements. A high-speed $\mathrm{OH}$ PLIF system with $\sim 1.8 \mathrm{~mJ} /$ pulse at $500 \mathrm{~Hz}$ is developed, and tests are conducted at a direct-connect supersonic combustion facility. In this paper, OH-PLIF signals and pressure were measured simultaneously, and flame dynamics during pressure buildup were investigated, with a special focus on the ignition and flameout processes. In addition, the flame trajectory of the ignition process is depicted. The results show that the time scale of flame development is consistent with that of pressure stability, whereas the pressure change lags the change in flame intensity. The flame structure is discussed in both scramjet and ramjet modes. An unstable flame structure develops in the ramjet mode, and the flame area decreases similarly in both combustion modes. Flame oscillations are captured for three hydrogen equivalence ratios.

Keywords: supersonic combustion, high-speed PLIF technique, flame evolution, oscillations, scramjet

\section{INTRODUCTION}

Scramjet engines are a vital part of air-breathing propulsion systems, and scramjet operation over a wide range of flight Mach number is of particular importance for meeting multiple mission requirements [1,2]. In addition, to obtain high specific impulse, considerable effort has focused on the hydrogen-fueled scramjet as opposed to hydrocarbon-fuel scramjet $[3,4]$. The wide operation range of the hydrogen-fueled scramjet engine depends on the transition between the combustion modes for maximum engine performance. Because of the high cost and high risk of flight tests, there is renewed interest in scramjet ground-test facilities [5, 6]. Such facilities include opticalmeasurement techniques, which are promising techniques to obtain the experimental data needed to understand the ram-to-scram transition mechanism [7, 8] and establish an optimal-scramjetcombustion-mode database.

At present, in addition to traditional pressure-measurement methods, laser-based measurements that may be applied to bench-test scramjets mainly include coherent anti-stokes 
Raman scattering [9], particle image velocimetry [10], tunable diode laser absorption tomography [11, 12], high-speed photography [13], schlieren [14], photothermal spectroscopy [15-17], photoacoustic spectroscopy [18], and planar laserinduced fluorescence (PLIF) [19]. The PLIF technique has been used in the laboratory to image flame structure from simple flames to large-scale combustors and has matured to the point where it now contributes significantly to the field of combustion diagnosis [20]. The hydroxyl $(\mathrm{OH})$ radical is one of the most important chemical intermediates occurring in combustion systems of interest. The OH-PLIF technique, on the other hand, has been shown to be a valuable tool regarding both qualitative characterizations of flame structure [21] and quantitative measurements of interesting features, such as concentration, temperature, and velocity [22-24]. To validate the numerical model, Johansen et al. [25] and McRae et al. [26] made $10-\mathrm{Hz}$ OH-PLIF measurements at the dual-mode supersonic combustion facility and reported the development of a highly turbulent flame structure. Wang et al. [27] conducted optical-diagnosis-based combustion experiments, including $\mathrm{OH}$ PLIF, $\mathrm{OH}$ spontaneous emission, high-speed framing of flame luminosity, and schlieren in a cavity-based supersonic combustor to characterize the combustion flow and study the effects of cavity configurations, fueling schemes, and equivalence ratios. They used OH-PLIF to visualize flame structure and represent different combustion modes. Boyce et al. [28] used OH-PLIF with a $10-\mathrm{Hz}$ laser repetition rate to characterize the combustion reaction in a supersonic combustion scramjet engine model. The combination of OH-PLIF and surface-pressure measurements revealed the hot pocket locations and the concentration of $\mathrm{OH}$ radicals. Tian et al. [29] investigated how the hydrogen equivalence ratio affects flow structure and flame development in a scramjet combustor by using OH-PLIF at $10 \mathrm{~Hz}$. Note also that unstable and oscillating flame structures appear in ramjet-mode operation [30]. Transitions between scramjet and ramjet modes were triggered by changing the equivalence ratio of hydrogen. However, the flame evolution, especially during the ignition process, could not be obtained due to the low laser repetition rate. As for high-speed measurements, Sun et al. [31] investigated the spark ignition process in the scramjet combustor using high-speed photography with 4,000 fps. The development and propagation process of flame were observed. Allison et al. [13] performed $50-\mathrm{kHz} \mathrm{CH}^{*}$ chemiluminescence imaging to study the mean heat-release characteristics and flame dynamic behavior. Obviously the above results have the problems of long exposure time and low spatial resolution.

Previous experience with the study of industrial combustors suggests that combustion instability may exist in scramjet engines [32]. Combustion instabilities including flame oscillation and combustion fluctuation are also of great significance in the combustion efficiency and even the safety of the combustion system [33-35]. The peak position variation of $\mathrm{OH}$ concentration was associated with the change of the reaction zone that corresponded with the fluctuation of the heat-release zone in the combustion chamber. A high-speed OH-PLIF system is capable of imaging flame structures and recording the dynamic evolution, and especially the temporal development of important features [36]. So the flame fluctuation can be tracked in real time, and combustion oscillations reflected by flame fluctuation can be investigated. However, most successful applications are confined to ideal laboratory environments and disregard the impact of the external environment (i.e., how variables such as temperature, humidity, and vibration affect the high-speed PLIF system). Scramjet bench measurements are commonly made in extremely complex conditions, which pose a substantial challenge for high-speed PLIF systems. The low-energy output of commercial high-speed PLIF systems and the stringent requirements of the working environment severely restrict the applications of scramjet bench testing. To overcome the problem of low repetition rate and low-energy output, a pulse-burst laser system, which offers a relatively high laser repetition rate and high energy output, may be used. However, only a few PLIF images are obtained in a cycle with these systems, so they cannot evaluate the entire combustion process on the time scale of seconds. Therefore, a continuous high-speed PLIF system with high laser energy is deemed suitable for a scramjet bench test [37].

At present, the relevant research mainly concentrates on low-speed PLIF measurements and high-speed photography to scramjet. However, limited by low spatial resolution and long exposure time, fine flame evolution processes cannot be obtained, although urgently essential. The flame dynamics of the whole combustion process in different combustion modes is strongly necessary to understand the ram-to-scram transition mechanism. Furthermore, the rare applications of high-speed PLIF technique may be attributed to the environmental factors of the scramjet bench. So we consider the several environmental factors and the scramjet bench on the PLIF system, and report herein the application of the $500-\mathrm{Hz}$ OH-PLIF technique to bench-test a scramjet. Firstly, we begin by establishing the relationship between the $\mathrm{OH}$ signal and wall pressure in the combustor. The experiment reveals the evolution of the flame structure during the pressure buildup coupled with wall pressure. Then, the flame morphology and development of the ramjet mode and the scramjet mode are obtained under different hydrogen equivalence ratios to further analyze the oscillations of the different combustion modes.

\section{EXPERIMENT}

In the laboratory environment, temperature and humidity are better controlled than in the field and the effect of dust is eliminated. The influence of vibration on the PLIF system is almost negligible. However, some characteristics of the benchtest environment strongly affect the stable operation of the high-speed PLIF measurement system and significantly weaken its detection capability. In the bench-test environments, the performance of the PLIF system can be severely affected by the external environment, especially temperature and humidity. Large temperature span $\left(10-35^{\circ} \mathrm{C}\right)$, large temperature variation $\left( \pm 5^{\circ} \mathrm{C}\right)$, and nearly $90 \%$ humidity largely affect the stability of the PLIF system. Large temperature variation can reduce the efficiency of frequency doubling, and high humidity may cause crystal deliquescence. In addition, the fluctuation of laser energy 


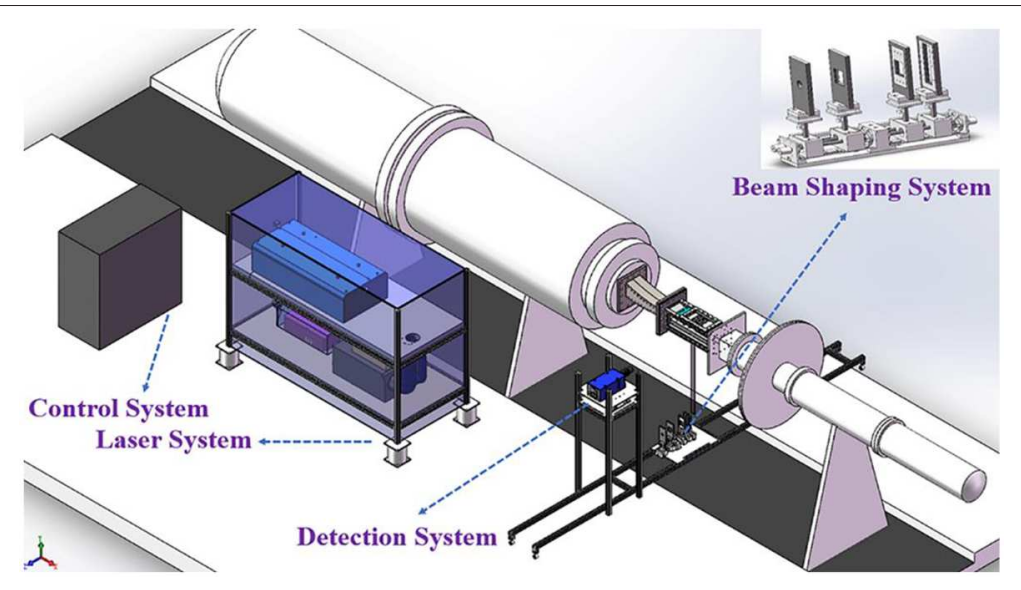

FIGURE 1 | Schematic of experimental apparatus.
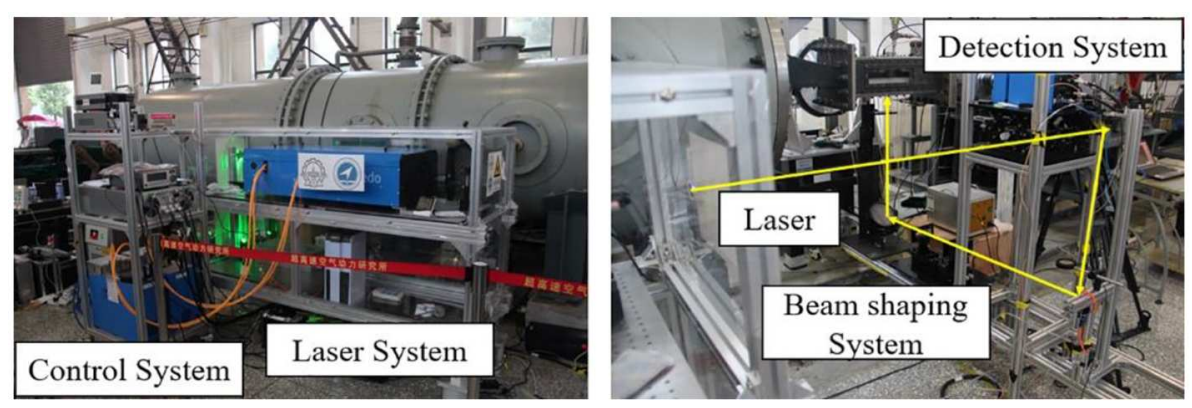

FIGURE 2 | Supersonic combustion facility and PLIF measurement equipment at CARDC.

and drift of the laser wavelength are other consequences of a bench that vibrates intensely. Meanwhile, intense vibration and copious dust may affect the optical system, or even damage the PLIF system. Thus, the harsh bench environment requires that the measurement system is adaptable to its environment. To ensure the stable operation of the PLIF system, we therefore developed a PLIF system that is highly adaptable to its environment (see Figure 1). The system has a modular design, almost free adjustment, may be controlled remotely, and offers antivibration and temperature-humidity control. The temperature was controlled at about $25^{\circ} \mathrm{C}$, and the jitter range was $<10 \%$. The humidity was reduced to $40 \%$. Specifically, the integrated beam-shaping system has much-improved stability and reliability. Note that the $500-\mathrm{Hz} \mathrm{Nd}$ : YAG laser was developed independently as the pumping source for the PLIF system, concentrating on the feature including higher laser repetition rate, larger energy output, and better stability under long operation. The peak of output energy can reach $30 \mathrm{~mJ} /$ pulse, and the energy variation is $<3 \%$; furthermore, the pumping source was filled with nitrogen to prevent moisture accumulation.

Figure 2 shows photographs of the OH-PLIF measurement system. The laser system consisted of a pulsed Nd: YAG laser frequency doubled in a BBO crystal and a dye laser with rhodamine 590. The second harmonic $(\lambda=532 \mathrm{~nm})$ of the $\mathrm{Nd}$ :
YAG laser pumped the dye laser. The dye laser was frequencydoubled to yield about $1.8 \mathrm{~mJ} / \mathrm{pulse}$ at a $500-\mathrm{Hz}$ repetition rate, and the laser pulse width is about 9 ns. To excite $\mathrm{OH}$ radicals, the Q1(8) line of the $A^{2} \Sigma^{+}-X^{2} \Pi(1,0)$ transition at $283.553 \mathrm{~nm}$ was used to reduce the temperature dependence of the fluorescence signal. In addition, a wavemeter (WaveMaster, Coherent, USA) was used to monitor the laser wavelength. The beam-shaping system consisted of a concave lens $(\mathrm{f}=-15 \mathrm{~mm})$, a collimating lens $(\mathrm{f}=350 \mathrm{~mm}$ ), and a focusing lens ( $\mathrm{f}=$ $275 \mathrm{~mm}$ ). The sheet-forming optics generated a 12 -cm laser sheet to provide sufficient area to visualize radicals. $\mathrm{OH}$ fluorescence was detected by using an ICMOS camera integrated in-house. A UV-achromatic lens (Nikon, F/105 mm, f/4.5) and a single-band bandpass filter combined with a Schott UG11 and a Semrock $315 / 15 \mathrm{~nm}$ brightline single-band bandpass optical filter were used to detect the $\mathrm{OH}$ signal and block scattered laser light. The detection gate time was set to $100 \mathrm{~ns}$ to minimize contributions of $\mathrm{OH}^{*}$ chemiluminescence and flame luminosity.

The experiments are carried out at a ground directed supersonic combustion facility [29]. The scramjet combustor simulates Mach 4 flight conditions by using high-enthalpy airflow, which is obtained by heating a hydrogen-air mixture. Stagnation conditions were $950 \mathrm{~K}$ and $0.8 \mathrm{MPa}$, and the Mach number at the isolator entrance was 2.0. Under test conditions, 


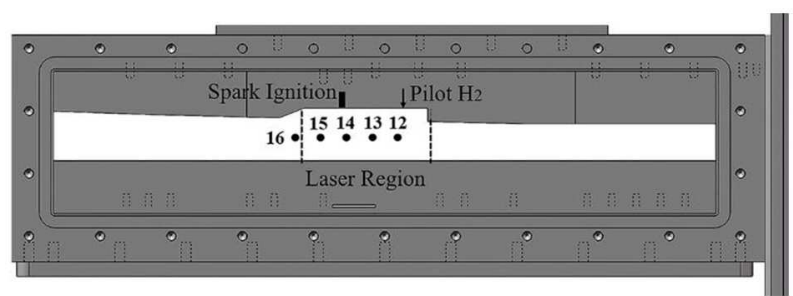

FIGURE 3 | Schematic of the supersonic combustor showing pressure points.

TABLE 1 | Experimental conditions.

\begin{tabular}{lcc}
\hline Condition & Hydrogen jet, MPa & Equivalent ratio \\
\hline A1 & 1.5 & 0.1 \\
A2 & 3 & 0.2 \\
A3 & 4.5 & 0.3 \\
\hline
\end{tabular}

the cavity length and depth were 121 and $11 \mathrm{~mm}$, respectively. The main flow direction is from right to left. The hydrogen was injected from the upstream injector (10 holes) inside the cavity, and the positions of hydrogen injection and spark plug ignition are shown in Figure 3. Pressure transducers (12-16) were arranged in the cavity at a sampling frequency of $1 \mathrm{kHz}$ to measure the wall-pressure distribution. The experimental conditions are given in Table 1.

\section{RESULTS AND DISCUSSION}

\subsection{Dynamic Evolution of Flame}

The $500-\mathrm{Hz}$ OH-PLIF system obtained data showing subtle flame-development features that reveal the dynamic characteristics of the flame. In the experiment, the change in combustor-wall pressure was used to determine the steady combustion field. Figure 4 shows the average pressure distribution under the condition A3. After ignition, heat release begins, and the pressure increases nearly equally between the pressure-measurement points. The pressure-stabilization time is about $14 \mathrm{~ms}$. To clearly show the evolution of the flame structure during the pressure-buildup process, the initial PLIF image is timed to correspond to the ignition time, and the time interval between images is $2 \mathrm{~ms}$. Low-speed PLIF, which typically uses a repetition rate of $10 \mathrm{~Hz}$, cannot capture the subtle evolution of the flame, which evolves on the timescale of milliseconds. Figure 5 shows the flame structure corresponding to the pressure curve for the condition A3. No flame appears at $0 \mathrm{~ms}$. The fire kernel forms initially within $2 \mathrm{~ms}$, and weak $\mathrm{OH}$ signals appear. The flame morphology stabilizes at $4 \mathrm{~ms}$ near the ignition plug. The flame gradually moves upstream due to increasing pressure with heat release [31], and then ignition occurs downstream of the combustion chamber. Next, a continuous pilot flame appears near the leading edge of the cavity and ignites the mixture of hydrogen and air. In addition, images of flameout are also captured clearly. Knowledge of the evolution

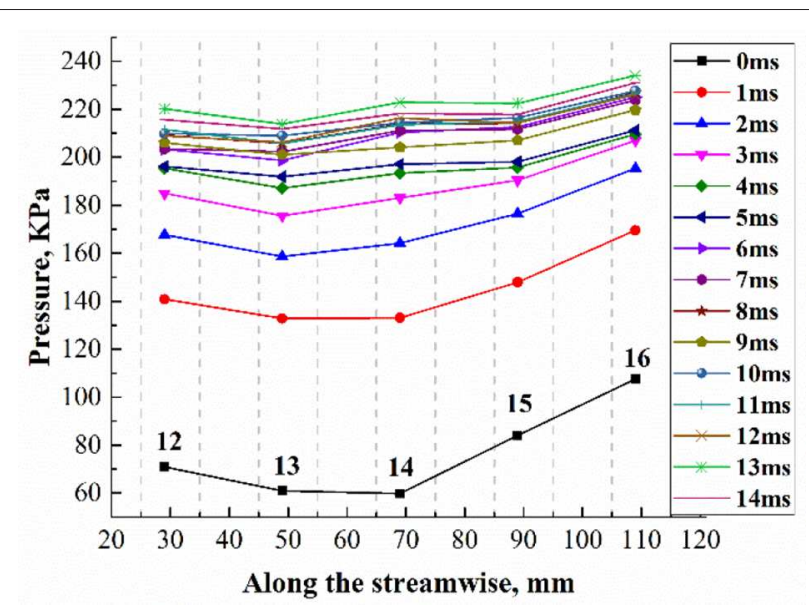

FIGURE 4 | Combustor-wall pressure distribution for condition A3, and the origin of the distance axis corresponds to the upper edge of the cavity. of the flame structure in which ignition occurs in scramjets can prove crucial for the cavity design and the optimization of combustion efficiency [38].

Acquiring quantitative $\mathrm{OH}$ concentrations from the raw PLIF images would require rigorous calibration. Obtaining accurate collision-quenching data for each species is almost impossible, especially in the complex flow field. However, the relative $\mathrm{OH}$ concentration is available from the intensity of the $\mathrm{OH}$ signal and suffices to study the combustion condition [28]. As mentioned above, the position of maximum $\mathrm{OH}$ signal strength is a flame feature that can be extracted to study the development of the flame in the combustor. Because of the high spatial and temporal resolutions of the high-speed PLIF technique, the flame trajectory can be captured in the ignition process. Figure $6 \mathrm{~A}$ shows the evolution of pressure during ignition and the flame trajectory. The time $t=0 \mathrm{~ms}$ corresponds to the onset of spark ignition. Analysis of the trajectory shows that the flame kernel begins near the ignition plug, following which the flame moves toward the hydrogen nozzle. In $6 \mathrm{~ms}$, the flame approaches the upper edge of the cavity, corresponding to the time when the overall $\mathrm{OH}$ signal stabilizes in the combustion chamber, as shown in Figure 6B. However, at the point, the pressure in the combustion chamber is not yet stable, as shown in Figure 6A. The results show that the flame structure and combustion intensity stabilize earlier than the pressure in the combustion chamber. Next, the pilot flame is near the hydrogen nozzle and gradually develops. The timescale of flame development is consistent with that of pressure stability. During this period, hot products from combustion carry the energy of ignition upstream through the recirculation zone [39], where heat is released and the flame can be held. The fuel appears to burn as a flame rather than via self-ignition [40].

\subsection{Visualization of Flame Structure}

The PLIF technique is preferred over other optical diagnostic techniques such as line-of-sight techniques (e.g., spontaneous 

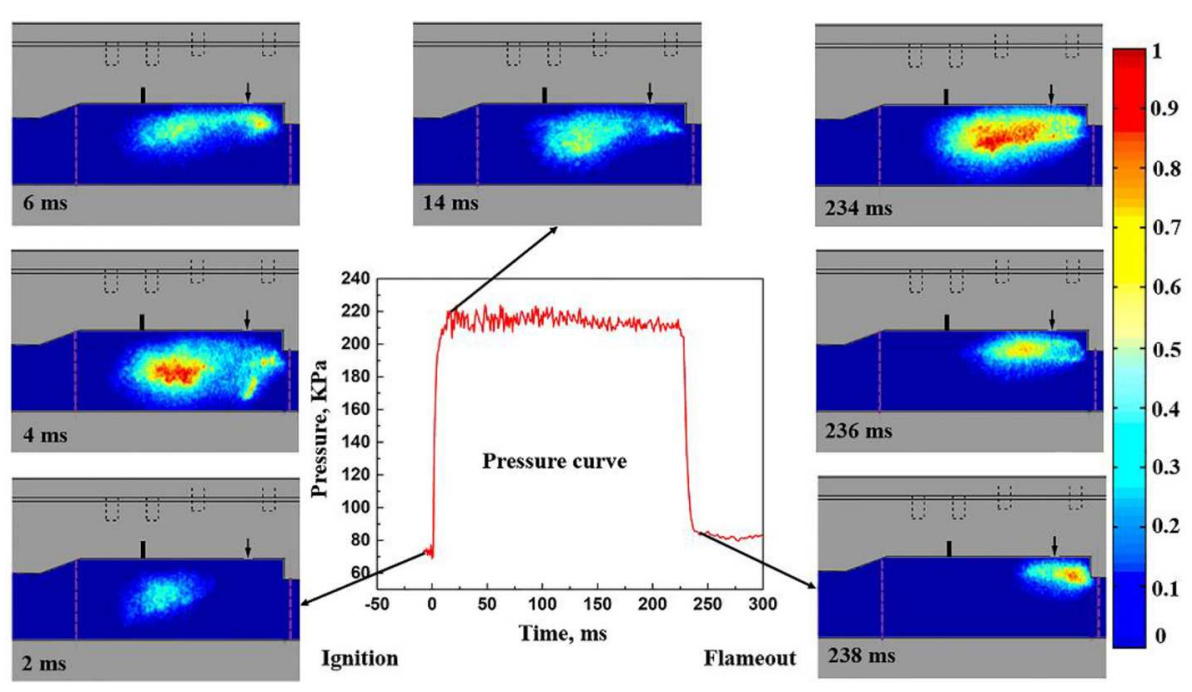

FIGURE 5 | OH-PLIF images and pressure curve from the ignition and flameout process under the equivalent ratio of hydrogen is 0.3.
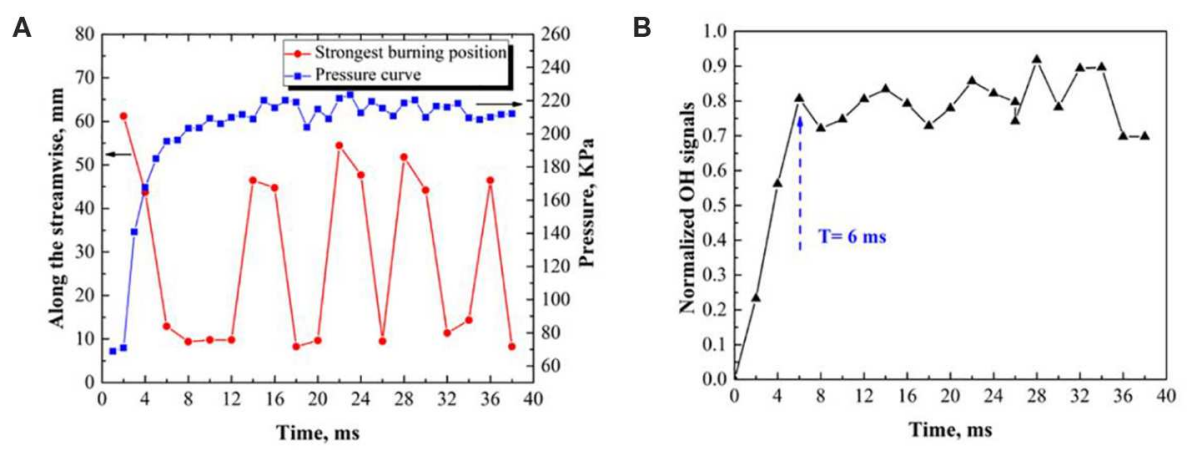

FIGURE 6 | (A) Flame trajectory of ignition (red) and pressure curve (blue) in the combustor, both as a function of time. (B) Growth and stabilization of OH signals in the ignition process.

radiation and schlieren) because it provides high spatial and temporal resolutions. According to Wang et al. [27] and Bao et al. [41, 42], three typical combustion modes exist in the hydrogen-fueled scramjet mode of the combustor, including the scramjet-mode, the transitional mode, and the ramjet mode, with each corresponding to different flame-stabilization modes. The equivalent ratio of hydrogen is an important factor in determining the mode transition.

In the experiment, to investigate flame morphology and the development of the different modes of operation of the combustor, we used conditions A1 and A3, which correspond to the scramjet mode and the ramjet mode, respectively. Figure 7 shows the images of the flame structures of two combustion modes during stable combustion. In Figure $7 \mathbf{A}$, the flame is downstream of the combustion chamber near the ignition plug in the scramjet mode. During flame evolution, only the flame intensity changes; the flame position and structure do not change because of the stable flame and flow structure in the shear layer in the scramjet mode [21]. In the ramjet mode, the flame essentially remains near the spark plug and hydrogen nozzle. Figure $\mathbf{7 B}$ shows the broken form of the flame. In each flame region, the flame is unstable and oscillating.

In addition to the effect of combustion mode on the flame structure, we also investigated the size of the combustion area of different modes (see Figure 8). The flame area gives the size of the combustion area. Firstly, aiming at the intensity distribution of $\mathrm{OH}$ signals, the appropriate threshold was found to identify the flame boundary, and then the binarization method was used to divide the flame region. Finally, combining the number of pixels in the flame region and spatial resolution, the flame area could be calculated. In both scramjet and ramjet modes, the flame area followed the same trend, which indicates that the combustion size is independent of the two stable combustion modes. In addition, the combustion area decreased slightly, which means the entire combustion zone is contracting in the scramjet combustor. In the transition mode, the combustion area changes 


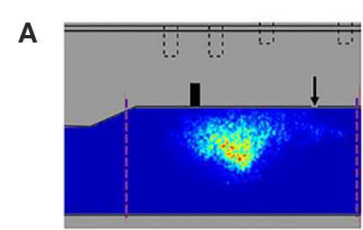

A1 condition

B

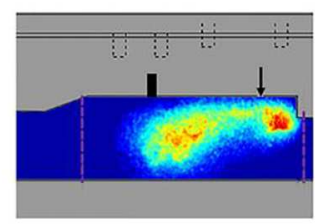

A3 condition
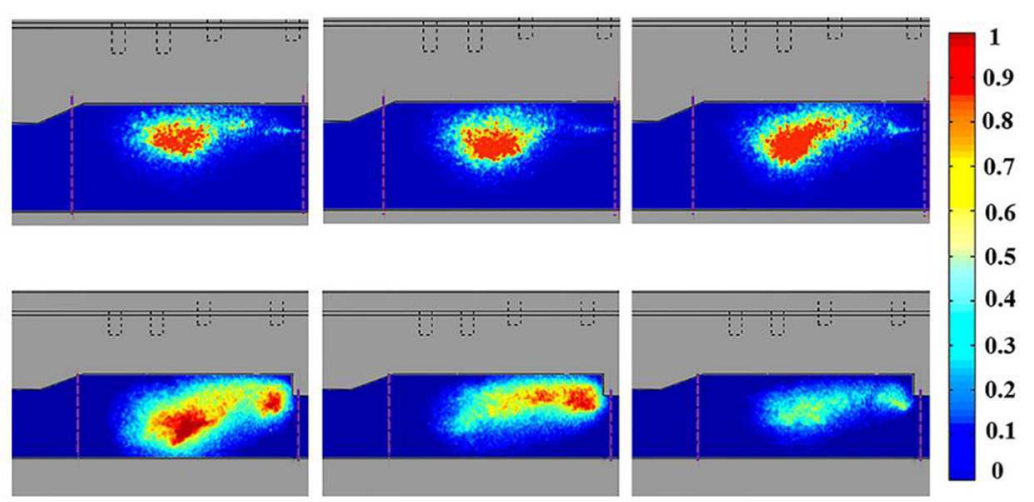

FIGURE 7 | Selected sequences of OH-PLIF images: (A) scramjet mode, (B) ramjet mode. The unit scale bar reflects the intensity of the normalized OH signal.

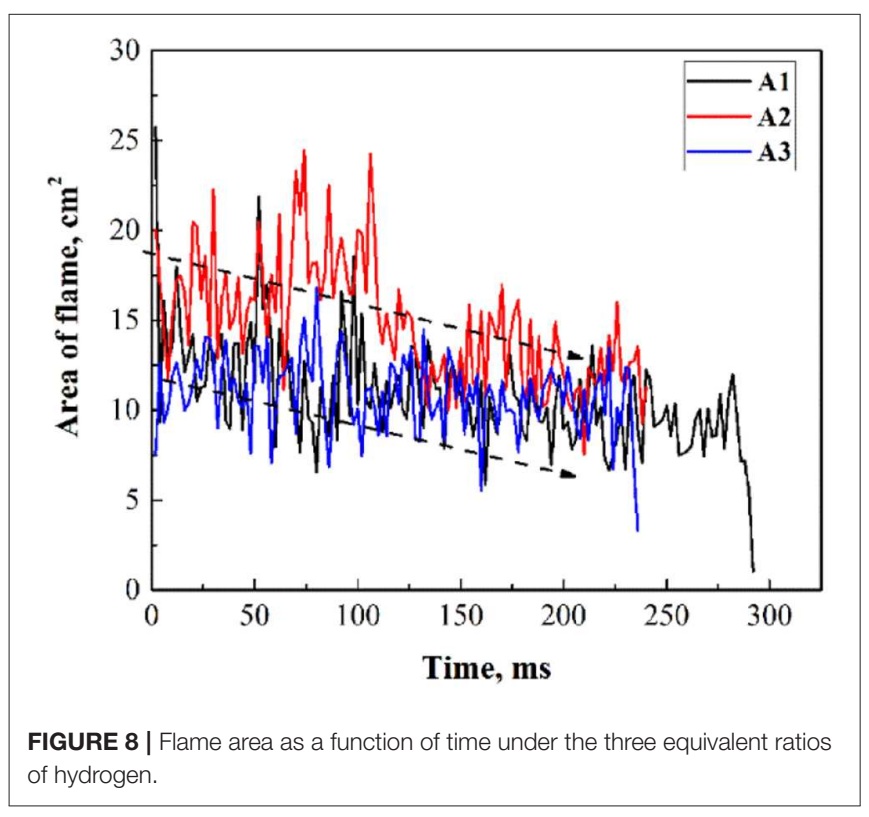

distinctly: the combustion area is significantly larger than in the stable mode.

\subsection{Characteristics of Flame Oscillations}

The 500-Hz OH-PLIF system reveals the characteristics of flame oscillations for three hydrogen equivalent ratios. Figures 911 plot the position that the maximum $\mathrm{OH}$ signal intensity occurs in the cavity as a function of time, revealing flame oscillations. To improve the accuracy of measurements, repeated experiments were carried out as shown in Figures 9B, 10B, 11B. It can be seen that the oscillations have better consistency under the same hydrogen equivalent ratio. In the early stage of combustion $(0-50 \mathrm{~ms})$, the flame oscillates between the ignition plug and the hydrogen jet, as shown in Figure 9A, but after $50 \mathrm{~ms}$, the flame position stabilizes downstream of the cavity, which means that the flow field and the flame shape are stable.
It may be speculated that a state of transition exists from oscillation to stability in the early stage of combustion. In Figure 10A, when the equivalent ratio of hydrogen is increased to 0.2 , similar oscillations occur in the early and latter stages of combustion, corresponding to the transitional mode of scramjet operation. As the equivalence ratio continues to increase, the oscillations almost overtake the entire combustion process, as shown in Figure 11A. The broken flame surfaces cause the $\mathrm{OH}$ signal to fluctuate, further contributing to the oscillations in combustion intensity.

Figures 12-14 show the wall pressures measured at points 12 and 14, which correspond to the positions of the ignition plug and the hydrogen jet, respectively. Meanwhile, the $\mathrm{OH}$ signal at the corresponding position serves to describe the combustion state. Some common features exist in the variations of pressure and the fluctuation of $\mathrm{OH}$ signals, so that the two develop similarly. Under condition A1, no difference appears in the pressure signal between the two positions within $50 \mathrm{~ms}$, and the $\mathrm{OH}$ signals are also entangled, as shown in Figure 12. After $50 \mathrm{~ms}$, two pressure curves separate, and the pressure at measuring point 14 exceeds that at measuring point 12 . Meanwhile, the $\mathrm{OH}$ signals follow the same pattern. As discussed above, the positions oscillate within $50 \mathrm{~ms}$; after $50 \mathrm{~ms}$, the oscillations disappear.

Upon increasing the hydrogen equivalent ratio (see Figure 13), the transition point shifts to $100 \mathrm{~ms}$. The same regularity appears and the oscillations also separate at $100 \mathrm{~ms}$. Upon increasing again the hydrogen equivalence ratio, the signals from the combustion chamber become flat. Similarly, the difference in $\mathrm{OH}$ signals between the two regions is neglected. The oscillations in the position overtake the entire combustion process, as shown in Figure 14. The dynamics of flame characteristics are clearly consistent with that of pressure. The results show that the flame oscillations occur because no gradient pressure exists in the combustor and the oscillations disappear when the pressure signals diverge at different measuring points. The OH-PLIF technique can proofread traditional pressure measurement method; meanwhile, it can 
A

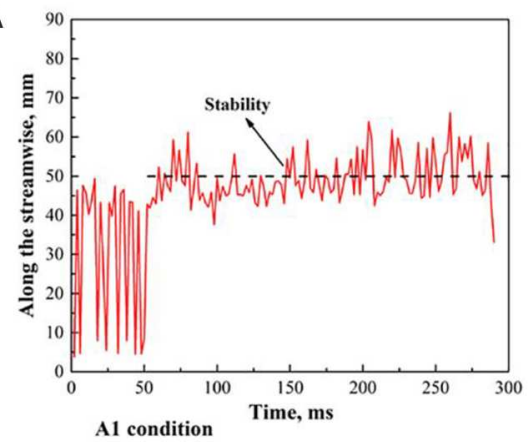

B

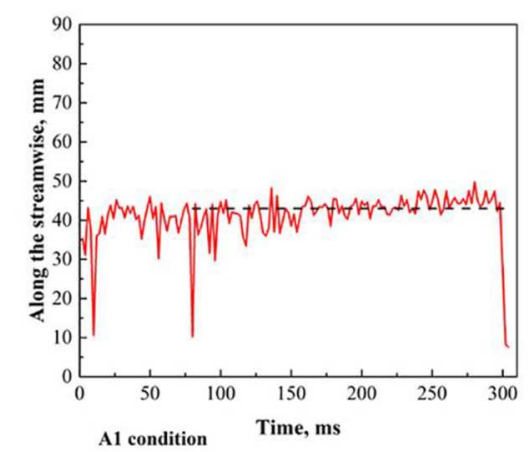

FIGURE 9 | The position that the maximum OH signal intensity occurs in the cavity as a function of time for A1 condition (A), and the repeated experiment result (B).

A

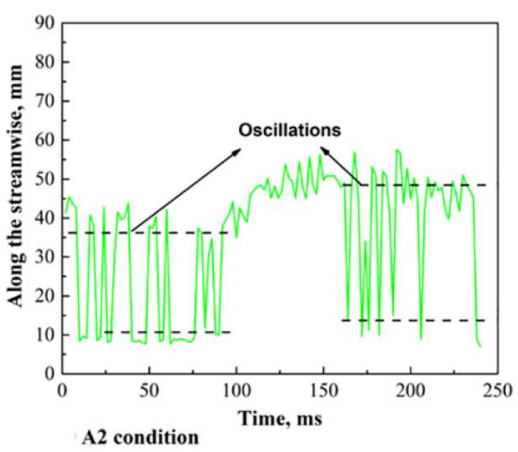

B

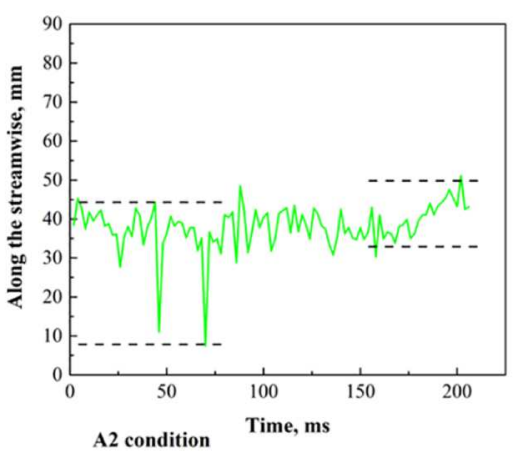

FIGURE 10 | The position that the maximum OH signal intensity occurs in the cavity as a function of time for A2 condition (A), and the repeated experiment result (B).
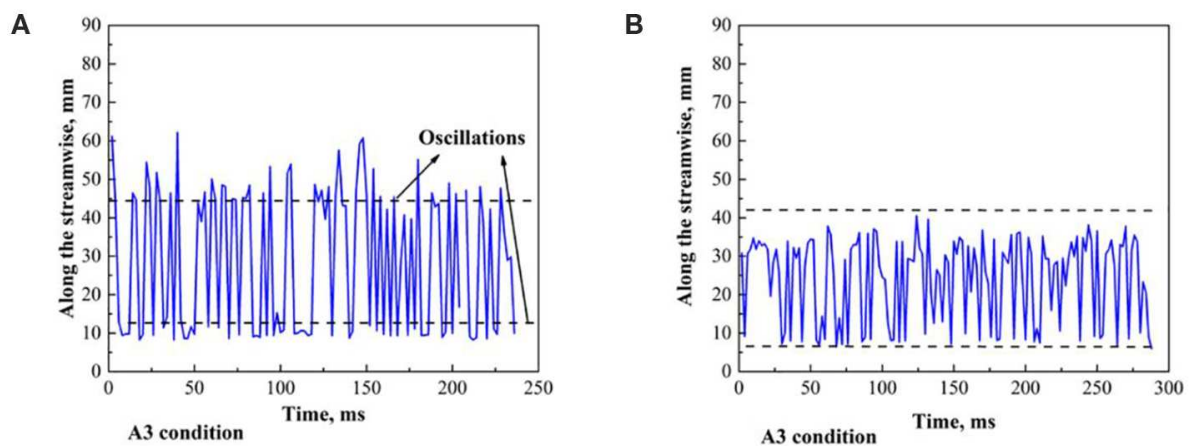

FIGURE 11 | The position that the maximum OH signal intensity occurs in the cavity as a function of time for A3 condition (A), and the repeated experiment result (B)

also be used as an important tool to study the combustion chamber oscillation.

\section{CONCLUSIONS}

The high-speed PLIF technique has great advantages over the high-speed photography in demonstrating fine flame evolution process. Considering complex environmental factors in the scramjet bench test, we developed an integrated high-speed OH-PLIF system with $\sim 1.8 \mathrm{~mJ} /$ pulse at $500 \mathrm{~Hz}$, and verified its environmental reliability at a direct-connect supersonic combustion facility. Compared with the lowspeed PLIF system (typically $10-\mathrm{Hz}$ repetition rate), the high-speed PLIF system can record the dynamic evolution of the flame, revealing the subtle trajectory of the flame during ignition. Moreover, the flame oscillation characteristics can be obtained and further investigated. In the scramjet mode, the flame is downstream of the combustion chamber near the ignition plug, and the flame oscillates between the ignition plug and the hydrogen jet in the early stage of 
A

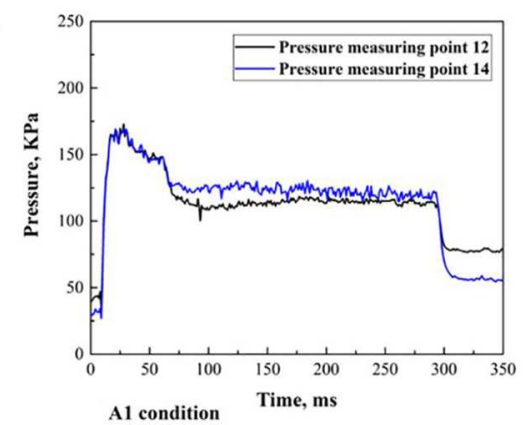

B

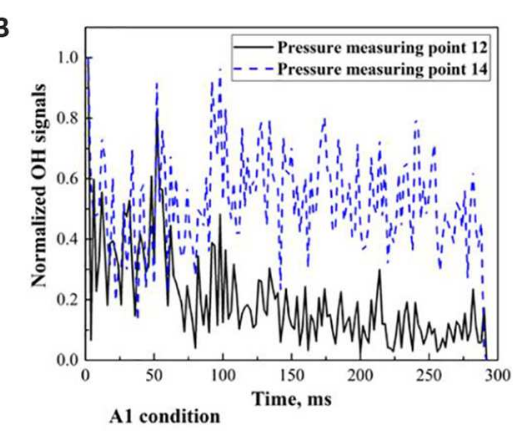

FIGURE 12 | A1 condition. Pressures at measurement points 12 and 14 (A), and average $\mathrm{OH}$ signals at measurement points 12 and 14 (B).

A

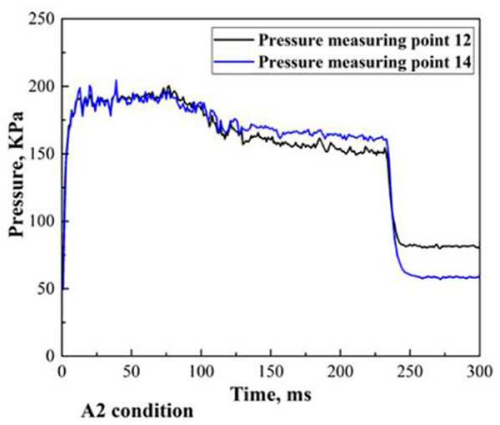

B

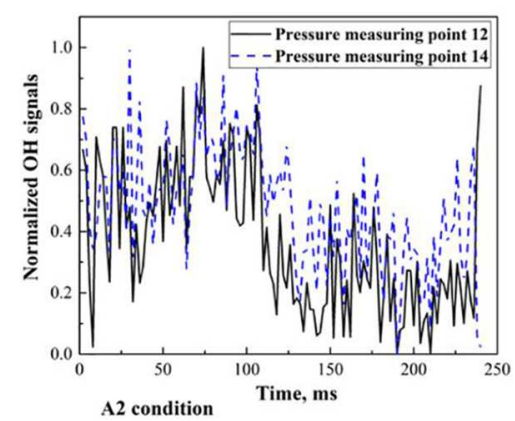

FIGURE 13 | A2 condition. Pressures at measurement points 12 and 14 (A), and average OH signals at measurement points 12 and 14 (B).

A

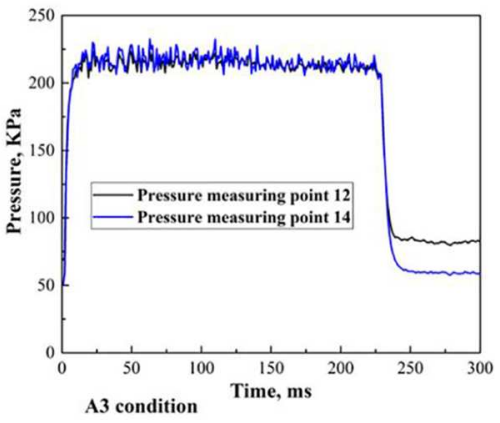

B

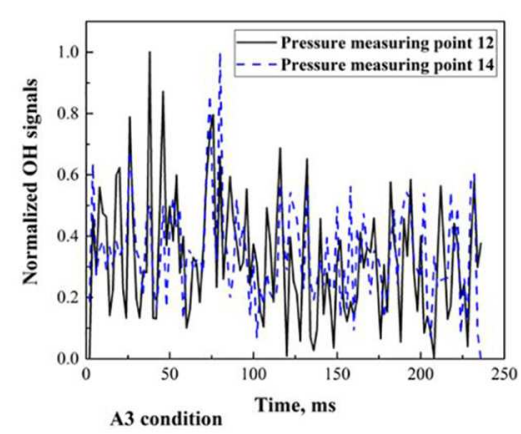

FIGURE 14 | A3 condition. Pressures at measurement points 12 and 14 (A), and average OH signals at measurement points 12 and 14 (B).

combustion (0-50 ms). In the ramjet mode, the flame essentially remains near the spark plug and the hydrogen nozzle; the flame structure is unstable and oscillating. Furthermore, the pressure and $\mathrm{OH}$ signals exist better consistency, such as the oscillation change point. The flame oscillations occur because no gradient pressure exists in the combustor and the oscillations disappear when the pressure signals diverge at different measuring points. The results show that coupled with pressure measurement, the timescale of flame development is consistent with that of pressure stabilization, whereas changes in pressure lag the changes in flame-combustion intensity. The main direction of future studies should be to increase the laser repetition frequency $(\sim \mathrm{kHz})$ to investigate the fire kernel development of the ignition process and to acquire more data on oscillations.

\section{DATA AVAILABILITY STATEMENT}

The datasets generated for this study are available on request to the corresponding author. 


\section{AUTHOR CONTRIBUTIONS}

$\mathrm{XY}$ and SY are the leader of the work. JP and ZC are responsible for experiment setting and paper writing. YY, GC, and SC are mainly engaged in picture editing and related data processing. SZ, HR, and YZ contribute to the stable operation of scramjet. BY and YL are responsible for

\section{REFERENCES}

1. Mahto NK, Choubey G, Suneetha L, Pandey KM. Effect of variation of length-to-depth ratio and mach number on the performance of a typical double cavity scramjet combustor. Acta Astronautica. (2016) 128:54050. doi: $10.1016 /$ j.actaastro.2016.08.010

2. Zhang D, Yang S, Zhang S, Qin J, Bao W. Thermodynamic analysis on optimum performance of scramjet engine at high mach numbers. Energy. (2015) 90:1046-54. doi: 10.1016/j.energy.2015.08.017

3. Cao R, Chang J, Tang J, Wang ZQ, Yu DR. Study on combustion mode transition of hydrogen fueled dual-mode scramjet engine based on thermodynamic cycle analysis. Int J Hydrog Energy. (2014) 39:212518. doi: 10.1016/j.ijhydene.2014.10.082

4. Qin F, Huang Z, He G, Wang S, Wei X, Liu B. Flame stabilization mechanism study in a hydrogen-fueled model supersonic combustor under different air inflow conditions. Int J Hydrog Energy. (2017) 42:2136070. doi: 10.1016/j.ijhydene.2017.06.237

5. Baccarella D, Liu Q, Passaro A, Lee T, Do H. Development and testing of the ACT-1 experimental facility for hypersonic combustion research. Meas Sci Technol. (2016) 27:045902-14. doi: 10.1088/0957-0233/27/4/045902

6. Seleznev RK, Surzhikov ST, Shang JS. A review of the scramjet experimental data base. Prog Aeosp Sci. (2019) 106:4370. doi: 10.1016/j.paerosci.2019.02.001

7. Huang W, Yan L. Numerical investigation on the ram-scram transition mechanism in a strut-based dual-mode scramjet combustor. Int. J. Hydrog. Energy. (2016) 41:4799-807. doi: 10.1016/j.ijhydene.2016.01.062

8. Huang W, Yan L, Tan J. Survey on the mode transition technique in combined cycle propulsion systems. Aerosp Sci Technol. (2014) 39:68591. doi: 10.1016/j.ast.2014.07.006

9. Cutler AD, Magnotti G, Cantu L, Gallo E, Rockwell R, Goyne C. Dual-Pump coherent anti-stokes raman spectroscopy measurements in a dual-mode scramjet. J Propul Power. (2014) 30:539-49. doi: 10.2514/1.B34964

10. Goyne CP, Rodriguez CG, Krauss RH, McDaniel JC, McClinton CR. Experimental and numerical study of a dual-mode scramjet combustor. $J$ Propul Power. (2012) 22:481-9. doi: 10.2514/1.13215

11. Busa KM, Bryner E, McDaniel J, Goyne CP, Smith CT. Demonstration of capability of water flux measurement in a scramjet combustor using tunable diode laser absorption tomography and stereoscopic PIV. In: 49th AIAA Aerospace Sciences Meeting including the New Horizons Forum and Aerospace Exposition (Orlando, FL), AIAA paper, 2011-1294 (2011).

12. Li G, Dong E, Ji W. A near-infrared trace $\mathrm{CO}_{2}$ detection system based on an $1,580 \mathrm{~nm}$ tunable diode laser using a cascaded integrator comb (CIC) filterassisted wavelength modulation technique and a digital lock-in amplifier. Front Phys. (2019) 7:199. doi: 10.3389/fphy.2019.00199

13. Allison PM, Frederickson K, Kirik JW., Rockwell RD, Lempert WR, Sutton JA. Investigation of supersonic combustion dynamics via $50 \mathrm{kHz}$ $\mathrm{CH} *$ Chemiluminescence Imaging. Proc Combust Inst. (2017) 36:284956. doi: 10.1016/j.proci.2016.08.039

14. Wang Y, Wang Z, Sun M, Wang H. Combustion stabilization modes in a hydrogen-fueled scramjet combustor at high stagnation temperature. Acta Astronautica. (2018) 152:112-22. doi: 10.1016/j.actaastro.2018.07.053

15. Ma YF, He Y, Tong Y, Yu X, Tittel FK. Quartz-tuning-fork enhanced photothermal spectroscopy for ultra-high sensitive trace gas detection. Opt Express. (2018) 26:32103-10. doi: 10.1364/OE.26.032103

16. He Y, Ma YF, Tong Y, Yu X, Tittel FK. Ultra-high sensitive light-induced thermoelastic spectroscopy sensor with a high Q-factor quartz tuning fork and a multipass cell. Opt. Lett. (2019) 44:1904-7. doi: 10.1364/OL.44.001904 experiment results. All have made positive contributions to the work.

\section{FUNDING}

This research was funded by the National Natural Science Foundation of China (Grant Nos. 61405048 and 91441130).

17. Ma YF, He Y, Patimisco P, Sampaolo A, Qiao S, Yu X, et al. Ultrahigh sensitive trace gas detection based on light-induced thermoelastic spectroscopy and a custom quartz tuning fork. Appl Phys Lett. (2020) 116:011103. doi: 10.1063/1.5129014

18. He Y, Ma YF, Tong Y, Yu X, Peng ZF, Gao J, et al. Long distance, distributed gas sensing based on micro-nano fiber evanescent wave quartz-enhanced photoacoustic spectroscopy. Appl Phys Lett. (2017) 111:241102. doi: 10.1063/1.5003121

19. Yu X, Chang G, Peng J, Dong H, Yu Y, Gao L, et al. Oxygen concentration distribution measurement of the nozzle flow field by toluene/acetone planar laser-induced fluorescence. Front Phys. (2019) 7:205. doi: 10.3389/fphy.2019.00205

20. Höinghaus KK., Barlow RS, Aldén M, Wolfrum J. Combustion at the focus: laser diagnostics and control. Proc Combust Inst. (2015) 30:89123. doi: $10.1016 /$ j.proci.2004.08.274

21. McRae, CD, Johansen CT, Danehy PM, Gallo E CA, Cantu L ML, et al. Image analysis of hydroxyl-radical planar laser-induced fluorescence in turbulent supersonic combustion. J Propul Power. (2015) 31:54259. doi: 10.2514/1.B35611

22. Versluis M, Georgiev N, Martinsson L. 2-D absolute $\mathrm{OH}$ concentration profiles in atmospheric flames using planar LIF in a bi-directional laser beam configuration. Appl Phys B. (1997) 65:411-7. doi: 10.1007/s003400050289

23. Bruchhausen $\mathrm{M}$, Guillard F, Lemoine F. Instantaneous measurement of two-dimensional temperature distributions by means of two-color planar laser induced fluorescence (PLIF). Exp Fluids. (2005) 38:12331. doi: 10.1007/s00348-004-0911-2

24. Frank JH, Kalt AM, Bilgera RW. Measurements of conditional velocities in turbulent premixed flames by simultaneous OH PLIF and PIV. Combust Flame. (1999) 116:220-32. doi: 10.1016/S0010-2180(98) 00041-8

25. Johansen CT, McRae CD, Danehy PM, Cantu LML, Magnotti G, Cutler AD, et al. OH PLIF visualization of the UVa supersonic combustion experiment: configuration A. J Vis. (2014) 17:131-41. doi: 10.1007/s12650-014-0197-2

26. McRae C, Johansen C, Danehy P, Gallo E, Cantu L, Magnotti G, et al. OH PLIF visualization of the UVa supersonic combustion experiment: configuration C. In: 51st AIAA Aerospace Sciences Meeting including the New Horizons Forum and Aerospace Exposition (Orlando, FL) (2013). 34 p.

27. Wang $\mathrm{H}$, Wang $\mathrm{Z}$, Sun $\mathrm{M}$, Wu H. Combustion modes of hydrogen jet combustion in a cavity-based supersonic combustor. Int J Hydrog Energy. (2013) 38:12078-89. doi: 10.1016/j.ijhydene.2013.06.132

28. Boyce, RR, Mudford, NR, McGuire, JR. OH-PLIF visualisation of radical farming supersonic combustion flows. Shock Waves. (2012) 22:9-21. doi: 10.1007/s00193-011-0346-7

29. Tian Y, Zeng X, Yang S, Zhong F, Le J. Experimental study on the effect of equivalence ratio and injector position on flow structure and flame development in the scramjet combustor. Aerosp Sci Technol. (2018) 82:919. doi: 10.1016/j.ast.2018.08.026

30. Tian Y, Yang S, Le J, Su T, Yue M, Zhong F, et al. Investigation of combustion and flame stabilization modes in a hydrogen fueled scramjet combustor. Int $J$ Hydrog Energy. (2016) 41:19218-30. doi: 10.1016/j.ijhydene.2016.07.219

31. Sun MB, Gong C, Zhang SP, Liang JH., Liu WD, Wang ZG. Spark ignition process in a scramjet combustor fueled by hydrogen and equipped with multi-cavities at mach 4 flight condition. Exp Therm Fluid Sci. (2012) 43:906. doi: 10.1016/j.expthermflusci.2012.03.028

32. Choi JY, Ma F, Yang V. Combustion oscillations in a scramjet engine combustor with transverse fuel injection. Proc Combust Inst. (2005) 30:28518. doi: 10.1016/j.proci.2004.08.250 
33. Wang H, Sun M, Qin N, Wu H, Wang Z. Characteristics of oscillations in supersonic open cavity flows. Flow Turbul Combust. (2013) 90:12142. doi: 10.1007/s10494-012-9434-8

34. Sun MB, Wang ZG, Liang JH, Geng H. Flame characteristics in supersonic combustor with hydrogen injection upstream of cavity flameholder. J Propul Power. (2008) 24:688-96. doi: 10.2514/1.34970

35. Wang $Z$, Sun $M$, Wang $H$, Yu J, Liang J, Zhuang $F$, et al. Mixing-related low frequency oscillation of combustion in an ethylene-fueled supersonic combustor. Proc Combust Inst. (2015) 35:2137-44. doi: 10.1016/j.proci.2014.09.005

36. Osborne JR, Ramji SA, Carter CD, Steinberg AM. Relationship between local reaction rate and flame structure in turbulent premixed flames from simultaneous $10 \mathrm{kHz}$ TPIV, OH PLIF, and $\mathrm{CH}_{2} \mathrm{O}$ PLIF. Proc Combust Inst. (2017) 36:1835-41. doi: 10.1016/j.proci.2016.07.124

37. Yang C, Peng J, Yu X, Fan R, Li X, Chen D. Continuous $100 \mathrm{~Hz}$ planar laserinduced fluorescence applied to the study of combustion processes. Spectr Lett. (2017) 50:265-9. doi: 10.1080/00387010.2017.1317270

38. Liu X, Cai Z, Tong $\mathrm{Y}$, Zheng $\mathrm{H}$. Investigation of transient ignition process in a cavity based scramjet combustor using combined ethylene injectors. Acta Astronautica. (2017) 137:1-7. doi: 10.1016/j.actaastro.2017.04.007

39. Li XP, Liu WD, Pan Y, Liu SJ. Investigation on ignition enhancement mechanism in a scramjet combustor with dual cavity. J Propul Power. (2016) 32:439-47. doi: 10.2514/1.B35880
40. Micka DJ, Driscoll JF. Combustion characteristics of a dual-mode scramjet combustor with cavity flameholder. Proc Combust Inst. (2009) 32:2397404. doi: 10.1016/j.proci.2008.06.192

41. Yang Q, Chang J, Bao W, Deng J. A mechanism of combustion mode transition for hydrogen fueled scramjet. Int J Hydrog Energy. (2014) 39:9791-7. doi: 10.1016/j.ijhydene.2014. 04.090

42. Cao R, Chang J, Bao W, Guo ML, Qin J, Yu D, et al. Analysis of combustion mode and operating route for hydrogen fueled scramjet engine. Int J Hydrog Energy. (2013) 38:5928-35. doi: 10.1016/j.ijhydene.2013. 02.135

Conflict of Interest: The authors declare that the research was conducted in the absence of any commercial or financial relationships that could be construed as a potential conflict of interest.

Copyright (c) 2020 Peng, Cao, Yu, Yang, Yu, Ren, Zhang, Chang, Chen, Zhao, Yan and Luo. This is an open-access article distributed under the terms of the Creative Commons Attribution License (CC BY). The use, distribution or reproduction in other forums is permitted, provided the original author(s) and the copyright owner(s) are credited and that the original publication in this journal is cited, in accordance with accepted academic practice. No use, distribution or reproduction is permitted which does not comply with these terms. 